\title{
A Stereological (Quantitative) Study of Leydig Cell Hyperplasia in Vasectomized Rabbit and Rat Testes
}

\author{
Hongni He ${ }^{1,2, \dagger}$, Zhen Tu${ }^{1,3, \dagger}$, Yang Guo ${ }^{4}$, Bin Peng ${ }^{4}, \mathrm{Li} \mathrm{Ma}^{4}$, Yi Shang ${ }^{5}$, Yugen $\mathrm{Li}^{1}$, \\ Xianzhong Deng ${ }^{1}$, Zhengwei Yang ${ }^{4}$, * \\ ${ }^{1}$ Department of Urological Surgery, The Affiliated Hospital of North Sichuan Medical College, Nanchong, China \\ ${ }^{2}$ Department of Gynecology and Obstetrics, the Nanchong Central Hospital, Nanchong, China \\ ${ }^{3}$ Department of Urological Surgery, the People's Hospital of Yuechi, Guang'an, China \\ ${ }^{4}$ Morphometric Research Laboratory, North Sichuan Medical College, Nanchong, China \\ ${ }^{5}$ Department of Gastroenterology, The Second Affiliated Hospital of North Sichuan Medical College, Nanchong, China
}

Email address:

357727619@qq.com (Hongni He), 495181232@qq.com (Zhen Tu),7827382@qq.com (Yang Guo), 340255492@qq.com (Bin Peng), mali8892011@163.com (Li Ma), 463525124@qq.com (Yi Shang),81799123@qq.com (Yugen Li), dengxz63@sina.com (Xianzhong Deng), zwyang@nsmc.edu.cn (Zhengwei Yang)

${ }^{*}$ Corresponding author

$\dagger$ Hongni He and Zhen Tu are co-first authors.

\section{To cite this article:}

Hongni He, Zhen Tu, Yang Guo, Bin Peng, Li Ma, Yi Shang, Yugen Li, Xianzhong Deng, Zhengwei Yang. A Stereological (Quantitative) Study of Leydig Cell Hyperplasia in Vasectomized Rabbit and Rat Testes. International Journal of Clinical Urology. Vol. 5, No. 1, 2021, pp. 4-9. doi: $10.11648 /$ j.ijcu. 20210501.12

Received: January 14, 2021; Accepted: January 21, 2021; Published: January 28, 2021

\begin{abstract}
It was speculated that vasectomy might induce hyperplasia of Leydig cells associated with atrophy of seminiferous tubules, but estimates of the Leydig cell number were lacking in previous studies. This study aimed to test the speculation by determining the numerical change of Leydig cells and other interstitial cells after a vasectomy that induced spermatogenic damage. Twelve adult Japanese white rabbits and twelve mature Sprague-Dawley rats were subjected to a unilateral vasectomy away from the scrotum. Six months (rabbits) or thirty-seven days (rats) postoperation, testes on both sides were removed and methacrylate sections prepared. The total numbers (per testis) of all nuclei in the testicular interstitial tissue were estimated with a stereological technique - the optical disector. The results showed that marked spermatogenic damage associated seminiferous tubular atrophy on the vasectomized side occurred in 7 (rabbits) or 5 (rats) of the 12 animals. For the rabbit, the total numbers of myoid cells or leukocytes on the vasectomized side (compared with the contralateral nonvasectomized side) were unchanged but those of Leydig cells and other interstitial cells increased significantly by $41 \%$ and $52 \%$, respectively, (a) with the increase in the testis with spermatogenic damage appearing to be larger than that in the testis without spermatogenic damage and (b) without significant increase in the total volume of the interstitium. For the rat, there were no significant differences in the total numbers of any cell type. In conclusion, hyperplasia or hyperproliferation of the interstitial cells, which might be a result of increased intra-testicular pressure for long, was possible postvasectomy, but it might not be indicative of a better function of the cells.
\end{abstract}

Keywords: Interstitial Tissue, Leydig Cells, Number, Rabbits, Rats, Stereology, Testis, Vasectomy

\section{Introduction}

In the 1920s, vasectomy was performed to rejuvenate older and fatigued men, assumed to be a result of atrophy of seminiferous tubules followed presumably by hyperplasia of Leydig cells in the inter-tubular interstitium which would presumably increase testosterone secretion [1-5]. Since its widespread use as a contraceptive measure from the 1950s, however, vasectomy has been shown by most studies not to affect significantly the serum testosterone levels 1 week to 25 
years after vasectomy in men [6-10]. Similarly in vasectomized rats, studies showed testosterone levels unchanged 1 week to 12 months postvasectomy [11-16]. It was recently suggested that vasectomy per se (vasal obstruction) would not lead to spermatogenic damage, which would result in seminiferous tubular atrophy, unless increased intra-testicular pressure was induced when the reproductive tract (including sperm granuloma formed around it) could not accommodate or dispose of the spermatozoa and testicular fluid continually produced by the testis after vasectomy [17-19]. Since the estimation of total Leydig cell numbers per testis, which could be obtained with an unbiased counting technique - the stereological optical disector [20,21], was lacking in previous studies, we speculated that the vasectomy-induced Leydig cell hyperplasia previously observed was a subjective impression on sections due to the tubular atrophy and therefore a relative increase of the interstitial tissue, i.e. due to, more precisely, the increase of Leydig cell numerical density (relative number or number per unit volume of testis) rather than the increase of absolute Leydig cell number. To test this speculation, the current study was therefore carried out to estimate the total numbers of Leydig cells (nuclei), and other interstitial cells, with the sophisticated stereological method and compare the total numbers of cells in the testes on the vasectomized sides with those on the non-vasectomized sides using a unilaterally vasectomized rabbit model [18] and a unilaterally vasectomized rat model [19], either of which successfully brought about a vasectomy-induced spermatogenic damage in some animals.

\section{Materials and Methods}

\subsection{Animals, Vasectomy and Tissue Blocks and Sections}

Methacrylate-embedded testicular tissue blocks re-used in this study were from our previous studies, in which the spermatogenic status in the seminiferous tubules and the total volume of the seminiferous tubules or interstitium were studied but the total numbers of the cells in the interstitium were not [18, 19]. Briefly, 12 normal adult male Japanese white rabbits (aged approximately 6 months) underwent a unilateral "proximal vasectomy": through a longitudinal ventral midline dermal incision between the pubic symphysis and the scrotum, the vas deferens on one side (left or right randomly chosen) was ligated with two ligatures (silk thread) and a segment of the vas was excised between the two ligatures. Twelve normal mature male Sprague-Dawley rats (aged 10-11 weeks) were subjected to a unilateral "distal vasectomy" via the inguinal canal: through a longitudinal incision in the inguinal region, the vas deferens on one side (randomly chosen) was doubly ligated with silk thread, but not severed. Six months (rabbits) or 37 days (rats) postoperation, both testes on the vasectomized side and the contralateral non-vasectomized side (control) were removed for study.
Two tissue blocks were obtained from each testis (in a random manner) and embedded in a resin (glycol methacrylate). One section (thickness $20 \mu \mathrm{m}$ ) was cut from each tissue block and each section was stained with periodic acid-Schiff's reagent and hematoxylin (Figures 1-4).

\subsection{Cell Number Estimation}

As we previously described [20-23], the numerical densities of all the cells (nuclei) in the interstitial tissue were first estimated with the stereological optical disector. Briefly, each testicular section was serially observed on a computer screen (final magnification on full screen $\times 2550$ ) through a $\times 100$ oil lens (Uplan FL N, numerical aperture 1.30) of an Olympus BX53 light microscope (Japan) equipped with a stereology system (NewCAST, Visiopharm, Denmark). Four forbidden-line frames (rectangular unbiased counting frames, each $24 \times 19 \mu \mathrm{m}^{2}$ ) were superimposed on each field of view; fields of view on each section were randomly sampled in a systematic (equally spaced) manner by means of a computer-assisted motorized stage (ProScan III, Prior Scientific Inc., USA), the distance between fields being set at $350 \mu \mathrm{m}$ along the $\mathrm{X}$-axis or Y-axis. From the focal plane (optical section) at $3 \mu \mathrm{m}$ below the top surface of the section, newly appeared nuclei of the cells in the interstitium were counted while focusing down through for $10 \mu \mathrm{m}$ (in thickness, measured with an electronic microcator by Dr. Johannes Heidenhain GmbH, Germany) of section, "within" each frame according to the optical disector counting rule. An average of 516 (rabbits) or 578 (rats) fields were sampled and an average of 482 (rabbits) or 544 (rats) nuclei counted per testis. The nuclear density was obtained by dividing the number of nuclei counted by the total volume of disectors (volume of each disector $24 \times 19 \times 10 \mu^{3}$ ) used for the counting. Then the total number of cells (nuclei) per testis was calculated by multiplying the numerical density by the volume of testis that was previously obtained $[18,19]$.

As described previously [18], the nucleated cells in the rat interstitium were divided into 4 categories readily identifiable: Leydig cells, myoid cells, leukocytes and other cells (including fibroblasts, endothelial cells, smooth muscle cells and others). Specifically, the large round Leydig cell nuclei are characterized by uniformly distributed granules of chromatin, the flattened myoid cell nuclei line the basement membrane of the seminiferous tubules, and the leukocyte nuclei are within the blood vessels (Figures 3 and 4). The nucleated cells in the rabbit were readily classified in the same way (Figures 1 and 2).

\subsection{Statistics}

The data in Table 1 and some in the text are expressed as mean \pm SEM (standard error of the mean). Comparison of data between the nonvasectomized and vasectomized sides of the same animals was performed using the paired t-test; the significance of difference was set at $\mathrm{p}<0.05$. 

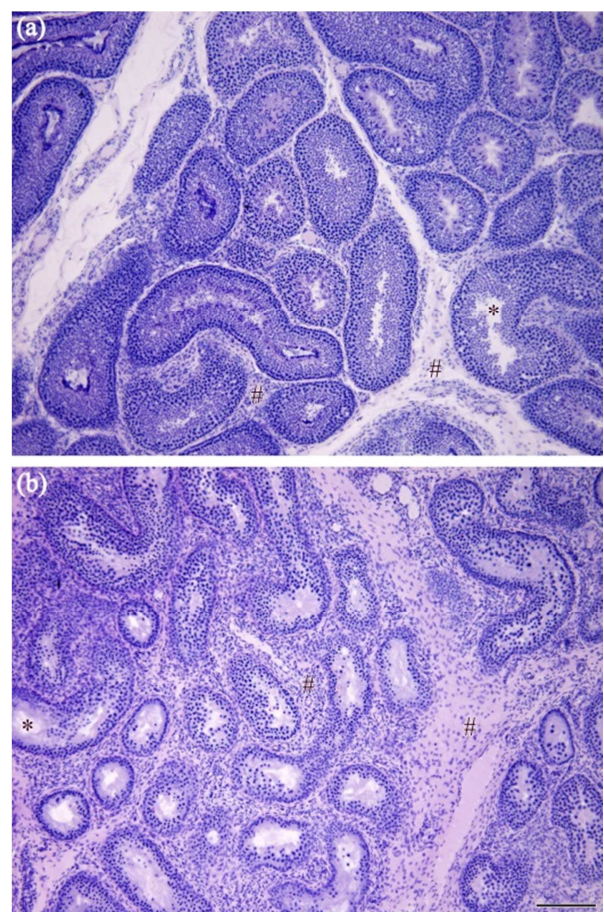

Figure 1. Typical micrographs taken with a $\times 10$ objective lens, from an adult rabbit testis on the nonvasectomized side (a) and an adult rabbit testis on the vasectomized side (b) at 6 months after unilateral vasectomy. *, lumen of seminiferous tubules; \#, interstitial tissue between seminiferous tubules. Note the atrophy of the seminiferous tubules and the relative increase of the interstitial tissue on the micrograph (b). Scale bar $=180 \mu \mathrm{m}$.

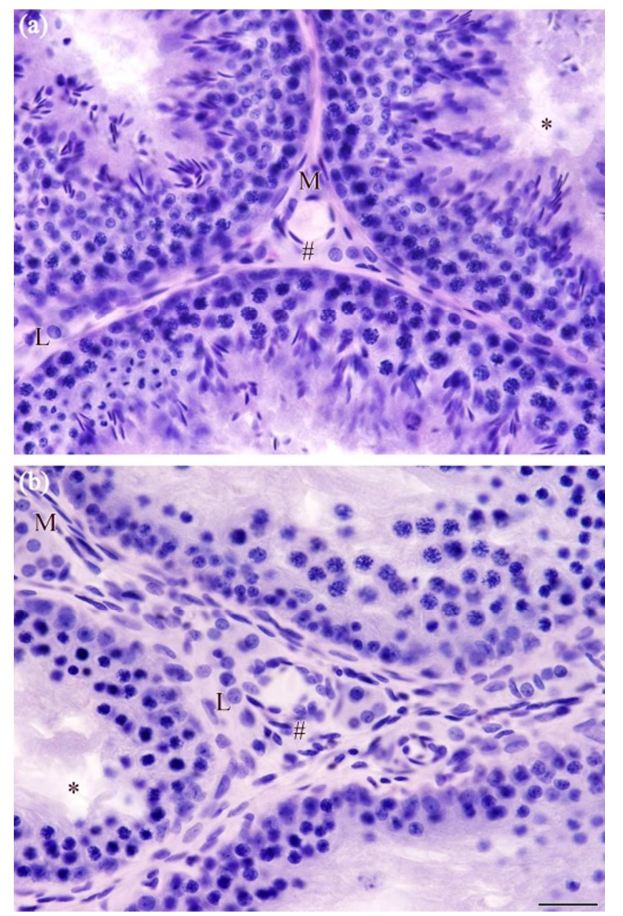

Figure 2. Typical micrographs taken with $a \times 60$ oil lens, from an adult rabbit testis on the nonvasectomized side (a) and an adult rabbit testis on the vasectomized side (b) at 6 months after unilateral vasectomy. *, lumen of seminiferous tubules; \#, interstitial tissue between seminiferous tubules; $L$, nuclei of Leydig cells; $M$, nuclei of myoid cells. Note the depletion of spermatids in the seminiferous tubules and the appearance of more flattened nuclei (fibroblasts, myoid or other cells other than Leydig cells) in the interstitial tissue on the micrograph (b). Scale bar $=30 \mu \mathrm{m}$.
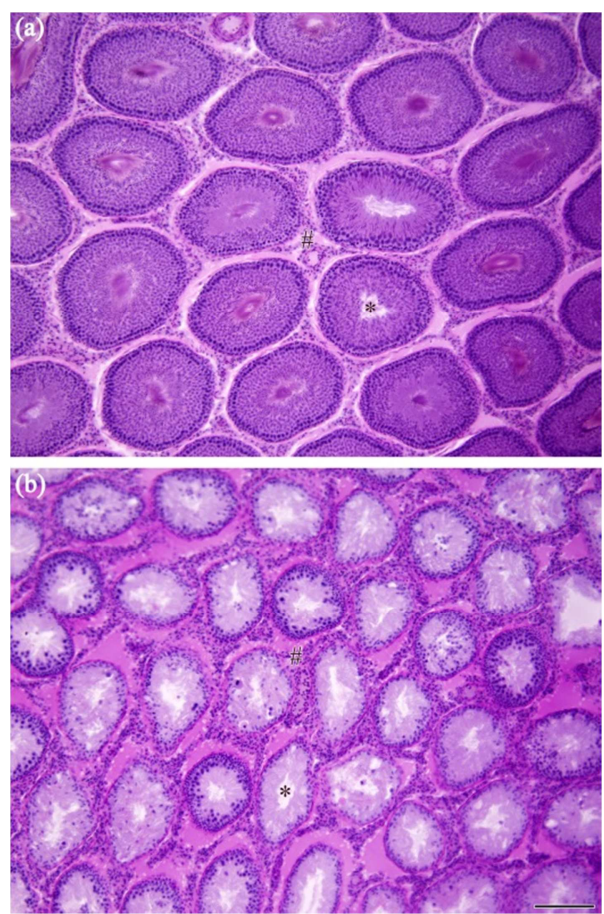

Figure 3. Typical micrographs taken with $a \times 10$ objective lens, from a mature rat testis on the nonvasectomized side (a) and a mature rat testis on the vasectomized side (b) at 37 days after unilateral vasectomy.*, lumen of seminiferous tubules; \#, interstitial tissue between seminiferous tubules. Note the severe atrophy of the seminiferous tubules on the micrograph (b). Scale bar $=180 \mu \mathrm{m}$.
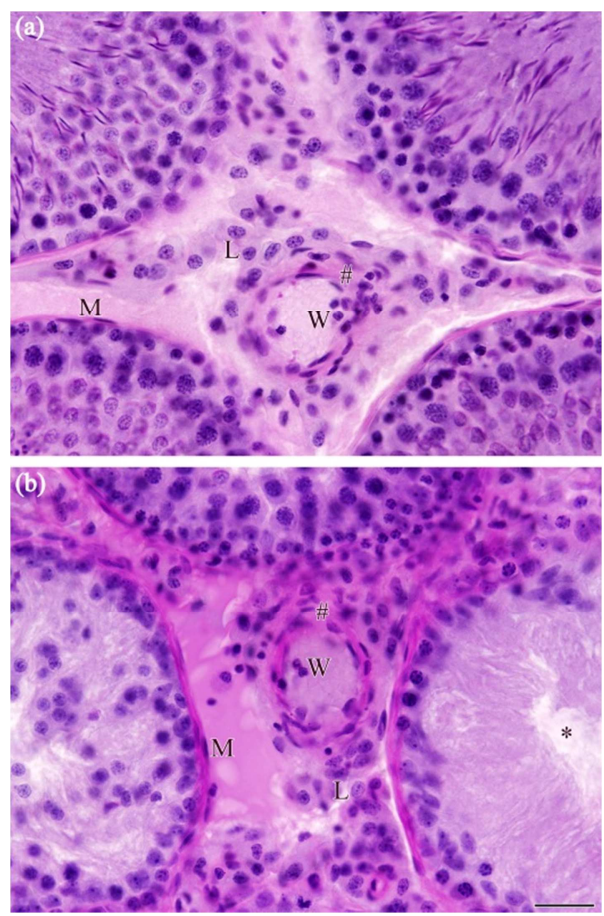

Figure 4. Typical micrographs taken with $a \times 60$ oil lens, from a mature rat testis on the nonvasectomized side (a) and a mature rat testis on the vasectomized side (b) at 37 days after unilateral vasectomy. *, lumen of seminiferous tubules; \#, interstitial tissue between seminiferous tubules; $L$, nuclei of Leydig cells; $M$, nuclei of myoid cells; $W$, nuclei of white blood cells. Note the depletion of spermatogenic cells (from spermatocytes to spermatids) in 2 seminiferous tubule profiles on the micrograph (b). Scale bar $=30 \mu \mathrm{m}$. 


\section{Results}

As shown previously [18, 19], the vasectomy induced marked spermatogenic damage (characterized by atrophied testis and seminiferous tubules with diminished adluminal spermatogenic cells) on the vasectomized side in 7 (rabbits) or 5 (rats) of the 12 animals (Figures 1-4 and Table 1). Based on data previously obtained $[18,19]$, the ratios of the total volume of the interstitial tissue on the vasectomized side to that on the nonvasectomized side were $1.233 \pm 0.189$ (for 7 rabbits with marked spermatogenic damage on the vasectomized side, $\mathrm{p}>0.40$ for comparison of the total volumes between the two sides) and $1.232 \pm 0.115$ (all 12 rabbits, $\mathrm{p}>0.10$ ), or $0.781 \pm 0.029$ (5 rats with marked spermatogenic damage on the vasectomized side, $\mathrm{p}<0.01)$ and $0.929 \pm 0.055$ (all 12 rats, $\mathrm{p}>0.05$ ).

Table 1. Total number (million per testis) of cell nuclei in the testicular interstitium.

\begin{tabular}{|c|c|c|c|c|}
\hline & \multicolumn{2}{|c|}{ Animals without spermatogenic damage ${ }^{*}$} & \multicolumn{2}{|c|}{ Animals with spermatogenic damage } \\
\hline & Nonvasectomized side & Vasectomized side & Nonvasectomized side & Vasectomized side \\
\hline \multicolumn{5}{|c|}{ Adult male Japanese white rabbits } \\
\hline Leydig cells $^{\mathrm{a}}$ & $51.0 \pm 5.6$ & $66.2 \pm 10.1^{\mathrm{b}}$ & $54.7 \pm 4.0$ & $81.7 \pm 12.2^{\mathrm{b}}$ \\
\hline Myoid cells & $21.6 \pm 2.8$ & $24.3 \pm 1.9$ & $24.0 \pm 1.9$ & $26.0 \pm 1.9$ \\
\hline Leukocytes & $1.9 \pm 0.4$ & $1.5 \pm 0.6$ & $1.2 \pm 0.3$ & $1.5 \pm 0.4$ \\
\hline Other cells ${ }^{\mathrm{a}}$ & $32.7 \pm 3.4$ & $42.9 \pm 8.6$ & $38.9 \pm 3.0$ & $62.1 \pm 6.9^{\mathrm{b}}$ \\
\hline \multicolumn{5}{|c|}{ Mature male Sprague-Dawley rats } \\
\hline Myoid cells & $7.3 \pm 0.5$ & $8.5 \pm 0.5$ & $7.5 \pm 0.5$ & $6.5 \pm 0.4$ \\
\hline Leukocytes $^{\mathrm{a}^{\prime}}$ & $0.8 \pm 0.1$ & $0.7 \pm 0.1$ & $0.8 \pm 0.1$ & $0.4 \pm 0.1$ \\
\hline Other cells $\mathrm{s}^{\mathrm{a}}$ & $16.2 \pm 1.6$ & $14.9 \pm 1.1$ & $17.2 \pm 1.8$ & $12.1 \pm 1.5^{\mathrm{b}}$ \\
\hline
\end{tabular}

Data are shown as $\overline{\mathrm{x}} \pm$ SEM. ${ }^{*}$ Marked damage to spermatogenesis in the testis on the vasectomized side occurred in 7 of the 12 rabbits at 6 months after unilateral vasectomy, or in 5 of the 12 rats at 37 days after unilateral vasectomy. Other cells: fibroblasts, endothelial cells, smooth muscle cells and others in the interstitial tissue. ${ }^{a} \mathrm{p}<0.05$ or ${ }^{\mathrm{a}} 0.05 \leq \mathrm{p}<0.10$ : for comparison between the nonvasectomized and vasectomized sides of all $(12)$ animals; ${ }^{b} \mathrm{p}<0.05$ or ${ }^{\mathrm{b}} 0.05 \leq \mathrm{p}<0.10$ : compared with the nonvasectomized sides of the same animals without or with spermatogenic damage.

In terms of qualitative histology observed on the sections of testis with spermatogenic damage on the vasectomized side (compared with the nonvasectomized side), the Leydig cell nuclei appeared slightly smaller and more irregular in the rat and there appeared to be more flattened nuclei (fibroblasts, myoid cells and others) in the rabbit (Figures 2 and 4). Apparent inflammatory cell infiltration, especially presence of typical neutrophils outside the blood vessels [18, 19], was not observed in the testis on either side.

For the rabbits $(n=7)$ with spermatogenic damage, the total numbers of Leydig cells and other interstitial cells (not including myoid cells or leukocytes) in the testes on the vasectomized sides (in comparison with the nonvasectomized sides $)$ increased by $50.3 \% \pm 22.4 \%(\mathrm{p}=0.06)$ and $67.8 \% \pm 26.0 \%$ $(p=0.03)$, respectively (Table 1$)$. For the rabbits $(n=5)$ without spermatogenic damage, the total numbers appeared to increase by $29.1 \%-29.2 \%(p=0.09-0.18)$. For all rabbits $(n=12)$, the total numbers significantly increased by $41.5 \% \pm 14.1 \%$ $(\mathrm{p}=0.01)$ and $51.7 \% \pm 16.8 \%(\mathrm{p}=0.01)$, respectively (Table 1$)$. For myoid cells or leukocytes, there were no significant differences in the total numbers between the vasectomized and nonvasectomized sides (Table 1).

For the rats, there were no significant increases $(p>0.05)$ in the total numbers of any cell type in the testes on the vasectomized side (in comparison with the nonvasectomized sides) and, in fact, the total numbers of Leydig cells and other interstitial cells (excluding myoid cells or leukocytes) appeared to have decreased by $13 \% \quad(\mathrm{P}=0.33)$ and $27 \%$ $(p=0.08)$ in the 5 testes with spermatogenic damage, respectively (Table 1$)$.

In terms of numerical density of Leydig cells (number per unit volume of testis), the results in the 12 rabbits significantly increased (vasectomized sides compared with nonvasectomized sides) by $81 \% \pm 27 \%(\mathrm{p}<0.01)$ and the results in the 12 rats appeared to have increased by $41 \% \pm 20 \%$ $(p=0.08)$.

\section{Discussion}

This is the third study in which we have estimated the total numbers of all interstitial cells in the testis with reliable stereological (quantitative) methods [18, 19] and the first study in which the total numbers of all interstitial cells have been estimated in the testis after vasectomy. The rabbit and rat models used in this study [18, 19] induced atrophy of the seminiferous tubules but not the inter-tubular interstitium, thus the numerical increases, if any, of interstitial cells postvasectomy would be more evident in numerical densities than absolute numbers. That is, we would tend to conclude that there was Leydig cell hyperplasia or hyperproliferation postvasectomy if we just observed histological changes on sections or calculated number of cells per area of section (Figures 1 and 3) or per unit volume of testis. As demonstrated in this study, the rat vasectomy that induced spermatogenic damage did not significantly increase the total numbers of Leydig cells or other interstitial cells, with the total numbers appearing to decrease and the numerical densities appearing to increase. Nevertheless, the rabbit vasectomy that induced spermatogenic damage increased not only the numerical densities but also the absolute numbers of Leydig cells and other interstitial cells (excluding myoid cells and leukocytes).

It should be pointed out that spermatogenic damage induced by vasectomy per se was intra-testicular pressure mediated $[18,19]$. Vasectomy via the scrotum might affect the testis as a 
result of iatrogenic effects of the operation such as inflammatory irritation or adhesion around the testis [24, 25]. Vasectomy away from the scrotum or testis might not affect the testis due to the distensibility of the reproductive tract (epididymis and vas deferens) and/or formation of sperm granuloma around the tract, which would accommodate and/or dispose of the spermatozoa and testicular fluid produced by the testis and thus relieve the intra-tract pressure or not affect the spermatozoa and testicular fluid being transported out of the testis, without resulting in increased intra-testicular pressure [17-19]. Specifically, the reproductive tract in the rabbit may distend for 3-6 months before sperm granuloma is formed $[17,18]$; the tract distension in the rat is rare but sperm granuloma may form soon after vasectomy [19]. Moreover, effect of vasectomy on the testis may be decreased with spermatogenic damage or reduced spermatogenesis [26]. So it is an advantage that the present study used a vasectomy away from the scrotum and that the vasectomy happened to induce increased intra-testicular pressure and thus spermatogenic damage, which might, more likely than a vasectomy that did not induce spermatogenic damage, affect the Leydig cells as well.

The vasectomy-induced hyperproliferation of Leydig cells and other interstitial cells (including fibroblasts, endothelial cells and smooth muscle cells) in the rabbit testis with spermatogenic damage, as demonstrated in the present study, appeared to be larger than that in the testis without spermatogenic damage. This suggested that the vasectomy-induced effect on the interstitial cells was also intra-testicular pressure mediated. The reason why the hyperproliferation did not occur in the present rat study might be species difference and, probably more likely, the shorter vasal obstructive interval. That is, persistent long-term vasal obstruction might more likely induce hyperproliferation of the interstitial cells while acute short-term vasal obstruction might less likely induce the hyperproliferation and more likely damage the interstitium or interstitial cells, which was supported by the total volume or number results (a trend of decrease rather than increase) in the rat. So the interstitial hyperplasia in the rat might also occur with increasing vasal obstructive intervals. But this will need clarification with further studies, and the clarification might be met with difficulty as longer vassal obstructive intervals do not necessarily lead to greater intra-testicular pressure or pressure-mediated testicular change (see above).

Taken together, the early speculation of Leydig cell hyperplasia following vasectomy-induced spermatogenic damage (see the Introduction) was possible, which was shown in the rabbit in the present study. But the hyperplasia was not Leydig cells specific. Concurrent hyperproliferation of connective tissue related cells (fibroblasts) and blood vessel related cells (endothelial cells and smooth muscle cells) shown in the present study was suggestive of a non-specific cell regeneration stimulated by the pressure onto the inter-tubular interstitium from the increased intra-tubular pressure. It is well recognized that fibroblasts, endothelial cells and smooth muscle cells are proliferative, regenerating from stem cells and existing cells [27]. As Leydig cells will regenerate 2 weeks after destruction with ethane dimethane sulfonate treatment [21], they have the potential of regeneration from stem cells. If vasectomy will indeed result in interstitial fibrosis [2, 26, 28, 29], hyperproliferation of fibroblasts will definitely be likely. As also shown in the rabbit, hyperproliferation of the interstitial cells was not associated with a significant increase in the total volume of the interstitial tissue, which implied overcrowding of the cells and thus poorer blood supply to or poorer function of the cells in the interstitium. This is supported by the fact that vasectomy is not normally associated with increased testosterone secretion (see the Introduction). Therefore the Leydig cell hyperplasia should be essentially a pathological change although it might be not worse than Leydig cell atrophy or depletion.

The use of both the rabbit and rat models in the present study was a study of 2 different experiments, not for model or species comparison. It is recognized that the mechanism of vasectomy-induced effects is mainly intra-reproductive tract and intra-testicular pressure mediated, unlikely via a systemic route such as immunity- or testosterone-mediated effects [18, 19]. Thus, to study the effects of vasectomy, it suffices to compare the vasectomized side with the contralateral nonvasectomized side in the same animal; in fact, such pair-design (within-animal bilateral comparison) is important (in terms of efficiency) for detecting the vasectomy effects, if any, in view of the considerable individual (between-animal) difference in the effects [25] as also shown in the current study. In other words, the use of the unilateral vasectomy model in the present study optimized comparison between the experiment (vasectomy) and control, conducive to reaching a conclusion that the effects found in the present study was due to the vasal obstruction per se (pressure-mediated local effects). And the conclusion, in principle, would not be affected even if the vasectomy induced some systemic effects (e.g. hormonal changes) as the systemic effects, which would unlikely affect the experiment (vasal obstruction), would affect both the vasectomized and non-vasectomized sides in the same way.

\section{Conclusion}

Hyperplasia of Leydig cells and other interstitial cells in the testis was induced at 6 months after a vasectomy away from the scrotum in the rabbit, probably a result of increased intra-testicular pressure for long after vasal obstruction, but not at 37 days after a vasectomy away from the scrotum in the rat, probably due to the fact that the vasal obstructive interval was acute and short.

\section{Competing Interests}

The authors declare that they have no competing interests.

\section{Acknowledgements}

This study was supported by North Sichuan Medical 
College and the Sichuan Youth Foundation of Science and Technology (grant No. 04ZQ026-025).

\section{References}

[1] Walker KM, Cook JAL. Steinach's rejuvenation operation. Lancet 1924; 203 (5240): 223-226.

[2] Gupta AS, Kothari LK, Bapna RB. Surgical sterilization by vasectomy and its effect on the structure and function of the testis in man. Br J Surg 1975; 62: 59-63.

[3] Lohiya NK, Dixit VP, Arya M. Long-term effects of vasectomy on the pituitary-gonadal system of rat and mouse. Endokrinologie 1976; 67: 152-159.

[4] Drake MJ, Mills IW, Cranston D. On the chequered history of vasectomy. BJU Int 1999; 84: 475-481.

[5] Kozminski MA, Bloom DA. A brief history of rejuvenation operations. J Urol 2012; 187: 1130-1134.

[6] Bunge RG. Plasma testosterone levels in man before and after vasectomy. Invest Urol 1972; 10: 9.

[7] Wieland RG, Hallberg MC, Zorn EM, Klein DE, Luria SS. Pituitary-gonadal function before and after vasectomy. Fertil Steril 1972; 23: 779-781.

[8] Nikkanen V, Punnonen R. Serum prolactin, FSH, LH and testosterone before and after vasectomy in normal men. Arch Androl 1982; 8: 311-313.

[9] Fisch H, Laor E, BarChama N, Witkin SS, Tolia BM, Reid RE. Detection of testicular endocrine abnormalities and their correlation with serum antisperm antibodies in men following vasectomy. J Urol 1989; 141: 1129-1132.

[10] Peng XS, Li FD, Miao ZR, Ye XM, Wong Y, Hu XZ, Zhong ZZ, Zeng FX, Wu XQ, Lan J, Li GZ, Jing SS, Farley TMM. Plasma reproductive hormones in normal and vasectomized Chinese males. Int J Androl 1987; 10: 471-479.

[11] Neaves WB. The androgen status of vasectomized rats. Endocrinology 1975; 96: 529-534.

[12] Mock EJ, Kamel F, Wright WW, Frankel AI. Plasma testosterone levels in vasectomized rats. J Reprod Fertil 1975; 44: 575-578.

[13] Kuwahara M. The effects of ligation of vas deferens, corpus epididymidis and vasa efferentia on the testicular function in rats. Tohoku J Exp Med 1976; 120: 251-257.

[14] Kinson GA, Narbaitz R, Bruce N. Gonadal function following vasectomy in the rat. Int J Fertil 1977; 22: 52-55.

[15] Aydos K, Kupeli B, Soygur T, Unsal A, Erden E, Tulunay O, Kupeli S. Analysis of the relationship between histologic alterations and the generation of reactive oxygen species in vasectomized rat testes. Urology 1998; 51: 510-515.

[16] Ren L, Weng Q, Kishimoto M, Watanabe G, Jaroenporn S, Taya K. Effect of short period vasectomy on FSH, LH, inhibinand testosterone secretions, and sperm motility in adult male rats. Exp Anim 2011; 60: 47-56.

[17] Peng B, Wang YP, Shang Y, Guo Y, Yang ZW. Effect of vasectomy via inguinal canal on spermatogenesis in rabbits. Asian J Androl 2008; 10: 486-493.

[18] Peng B, Mao Y, Tang XF, Shang Y, Shen CY, Guo Y, Xiang Y, Yang ZW. Comparison of spermatogenic damage induced at 6 months after ligation of the vas deferens at proximal and distal locations in the rabbit. Andrologia 2011; 43: 129-138.

[19] Ma L, Guo Y, Yuan Y, Li YG, Deng XZ, Yang ZW. Morphometric study of the testis and reproductive tract (including sperm granuloma) after vasectomy in mature rats. Asian J Androl 2016; 18: 66-73.

[20] Yang ZW, Guo Y, Lin L, Wang XH, Tong JS, Zhang GY. Quantitative (stereological) study of incomplete spermatogenic suppression induced by testosterone undecanoate injection in rats. Asian J Androl 2004; 6: 291-297.

[21] Yang ZW, Kong LS, Guo Y, Yin JQ, Mills N. Histological changes of the testis and epididymis in adult rats as a result of Leydig cell destruction after ethane dimethane sulfonate treatment: a morphometric study. Asian J Androl 2006; 8: 289-299.

[22] Xu W, Guo Y, Xiang Y, Yang ZW. Is there section deformation resulting in differential change of nuclear numerical densities along the $\mathrm{z}$ axis of thick methacrylate or paraffin sections? Microsc Res Techniq 2019; 82: 1575-1583.

[23] Guo Y, Li JM, Xiang Y, Li YY, Huang J, Deng XZ, Yang ZW. Quantitative (stereological) study of the epididymis and seminal vesicle in the rat from young to old. Andrologia 2019; 51: e13247.

[24] Peng B, Zhang RD, Dai XS, Deng XZ, Wan Y, Yang ZW. Quantitative (stereological) study of the effects of vasectomy on spermatogenesis in rhesus monkeys (Macaca mulatta). Reproduction 2002; 124: 847-856.

[25] Kong LS, Huang AP, Deng XZ, Yang ZW. Quantitative (stereological) study of the effects of vasectomy on spermatogenesis in rabbits. J Anat 2004; 205: 147-156.

[26] Xiang Y, Luo P, Cao Y, Yang ZW. Long-term effect of vasectomy on spermatogenesis in men: a morphometric study. Asian J Androl 2013; 15: 434-436.

[27] Gartner LP, Hiatt JI. Color atlas and text of histology. Baltimore: Lippincott Williams \& Wilkins. 2014.

[28] Mehrotra R, Nath P, Tandon P, Singh KM, Kumar H. Ultrastructural appearances of interstitial tissue of testis in vasectomised individuals. Indian J Med Res 1983; 77: 347-352.

[29] Raleigh D, O'Donnell L, Southwick GJ, de Kretser DM, McLachlan RI. Stereological analysis of the human testis after vasectomy indicates impairment of spermatogenic efficiency with increasing obstructive interval. Fertil Steril 2004; 81: 1595-1603. 